\title{
Insurance's impact on food safety and food security
}

\section{National University of food Technologies, Kyiv, Ukraine}

Mykhailo Arych

\begin{abstract}
The research analyzes the impact and role of insurance in ensuring and improving food safety and food security in accordance with international and national experience. The findings reveal that food security and safety is one of the biggest issue today facing humanity, but insurance can be a big instrument to mitigate to food safety and security risks.

The study also suggest that there are a lot of effective methods providing food safety and security. The analysis shows that there are four types of insurance product related to the food safety and security: commercial general liability; business interruption; product recall; product liability. Liability insurance has influence and contribute to food safety by follows reasons and methods as follows: reduction the insurance premiums; terms and conditions of the insurance policies; insurance companies' assistance with the aim to reduce food safety risks. The results indicate, that liability law could have influence of food safety and food security (liability claims; liability insurance; direct effects of liability law on management strategy).
\end{abstract}

Keywords: insurance, liability insurance, food industry, food safety, food security.

Corresponding author: Mykhailo Arych

E-mail: mykhailo.arych@gmail.com

DOI: $10.24263 /$ RES-2018-9

\section{Introduction}

The analysis of studies and publications showed that a lot of researchers are engaged in research into the insurance market and food safety and food security. The purpose of the study is to analyse the main interconnections of insurance and food safety and food security.

The complexity of the food safety and security problem justifies the performance of researches not only in agriculture, but in other branches of activity too. The insurance is to be noted by its struggles to adapt to the new challenges [10]. According to the Lloyd's Food Report (2013) insurance can be a big instrument to mitigate and management related to food safety and security risks (financial risks for growers, manufacturers, distributors, retailers and food-service providers) [1]. In addition, innovative insurance methods and multi-stakeholder cooperation can make a big impact in progressing towards a more food security and safety [1]. 
Food security and safety is one of the biggest problem and issue today facing humanity [10]. There are a lot of modern and effective methods and instruments providing food safety and security, but this article develops the influence of insurance on food safety and security. In addition, according to the Lloyd's Food Report (2013) food insecurity will be one of the issue to global society in the future [1]. Besides, Swiss Reinsurance Company Ltd (2015) indicates, for example, the insurance products for food contamination and studies the crisis management in food safety in a globalized world in in the 21st century [2]. The impact of insurance for food safety and security are object of studying for many scientists and international organizations across the world. Lloyd's analyzes the business and insurance implications of food safety and security [1]. Havinga (2012) discussed the influence of liability law (preventive effects of liability claims and liability insurance) on food safety, and stated that three ways in which liability law could have influence of food safety controls as follows [6]:

- liability claims;

- liability insurance;

- direct effects of liability law on management strategy [6].

This paper presents research into two parts: firstly, liability insurance and food safety; and, secondly, insurance and food security.

\section{Materials and methods}

\section{Materials}

The study of the insurance's impact on food safety and food security was conducted on the international scientific researches and reports. The most important research results were obtained from studies as follow: Swiss Reinsurance Company Ltd (2015) [2]; Connally (2009) [3]; Havinga (2012) [6]; Cogan and Aloysius (2016) [8]; Omri Ben-Shahar (2015) [5]; Isaboke et al. (2016) [9]; Mârzaa et al. (2015) [10] etc.

\section{Methods}

Scientific research of the insurance's impact on food safety and food security was based on the application of the following methods: abstract-logical, system analysis and grouping for studying the insurance's impact on food safety and food security. Observation, generalizations and descriptions methods were used to analyse the advantages and disadvantages of using insurance as instrument to increase the food safety and food security. 


\section{Results and discussion}

\section{Liability insurance and food safety}

Studying the crisis management in food safety in a globalized world in in the $21 \mathrm{st}$ century the Swiss Reinsurance Company Ltd (2015) shows that there are three insurance products for food contamination as follows [2]:

1) Product liability insurance (compensation of third party liability claims for injury or damage caused by the contaminated food);

2) Product recall insurance (food industry): expenses for the recall of any accidentally contaminated;

3) Contamination products insurance [2].

Altogether, according to the Connally (2009) it can be four types of insurance product related to the food safety and security: commercial general liability; business interruption; product recall; product liability [3]. Furthermore, insurers may also encourage safe food handling practices through the terms and conditions of the insurance agreement or by decreasing the insurance premiums based on the level of food safety [3].

Havinga (2012) have proposed three ways in which liability law could induce preventive measures for food safety as follows [6]:

1) Claims from injured consumers or damaged business.

2) Covering the risks of liability claims by insuring the risk (through insurance). Insurers may induce food safety controls through the terms of an insurance policy

3. Liability law has impact on business directly inducing businesses to assure food safety [6].

In addition, Cogan and Aloysius (2016) have proposed that combined these three methodologically distinct approaches food safety liability insurance is a weak regulator of food safety [8].

Analysis by Havinga (2012) shows that liability insurance has influence and contribute to food safety by follows reasons and methods [6]:

- reduction the insurance premiums;

- terms and conditions of the insurance policies;

- insurance companies assistance with the aim to reduce food safety risks [6].

The opposite arguments and measures to the positive insurance contribute to food safety are as follows [6]:

1) insufficient knowledge with insurers;

2) decreasing the financial incentive to produce safe food;

3 ) insurers does not interact with food safety officers [6].

Altogether, scholars have argued that that compulsory food safety liability insurance could supplement government regulation of food safety. As a result, Cogan and Aloysius (2016) stated that governments are exploring the benefits of food safety insurance [8]. 
Connally (2009) studied the problem of managing risks to reduce or avoid legal liability through the good food safety practices (GFSP) and argued that for the food industry enterprises with insurance, the policy may require the food supplier to follow the GFSP and do what is possible to minimize the incident of foodborne illness [3].

Omri Ben-Shahar (2015) explores regulation of food safety through compulsory insurance and the role of insurance as a substitute for government regulation of food safety. The results of the research papers show that the insurance sector has advantages in collecting and administering the information relevant to setting standards. Additionally, compulsory food liability insurance is an important way in which regulation of food safety [5].

In addition, Havinga (2012) argued that liability law could stimulate a culture within firms to take responsibility for food safety. Altogether, author distinguished the factors that encourage food safety measures in firms as follows:

1. Market (firms that produce unsafe food risk losing their reputation, market share and sales);

2. Food safety laws and regulations (firms that violate food laws risk penalties);

3. Product liability law (firms that are legally responsible for a product) [6].

Cogan and Aloysius (2016) have make research about the liability insurance as a regulator of food safety through three distinct perspectives as follows [8]:

- an economics of information framework;

- an analysis of the empirical evidence of under deterrence of foodborne illness;

- a review of emerging evidence of food suppliers' cognitive biases with regard to food safety.

\section{Insurance and food security}

In addition, according to the report of the Agricultural Insurance Conference (Berlin, 2014) agricultural insurance should be seen as one component to the agricultural system and it is related to food security [11].

Altogether, Isaboke et al. (2016) described the effect of weather index based microinsurance on food security status of smallholders, and find that a positive impact on food security is associated with the uptake of index insurance [9]. Mârzaa et al. (2015) suggest that insurance alone cannot provide food security. It can make a big impact in raising awareness of the importance of risk reducing and encouraging investments in increasing the agricultural industry development [10].

The research results by Isaboke et al. (2016) showed that many factors (age of household head, education level, household size, access to extension, distance to nearest market) are important variables that influence farmer's propensity to adopt the weather index insurance [9]. 
Mârzaa et al. (2015) discussed the interconnections between insurance and food security taking into account the climate change challenges. Authors have the ways in which insurance has a big impact for the food security as follows [10]:

1. Food security factors;

2. Factors impacting on the development of agricultural insurances;

3. European agricultural insurance systems [10].

Massachusetts department of agricultural resources analyzes the interconnection the food security and liability insurance. Scientific organization argued that buyers may have special concerns about food safety and they may require the producers to buy special insurance to protect them [4].

\section{Conclusion}

The article has investigated the practice of using insurance as an instrument for improving and ensuring food safety and food security in modern conditions. The results have indicated that insurance has a big impact for the food security in follow directions: food security factors; factors influencing the development of agricultural insurances; European agricultural insurance systems. The analysis shows that liability law could induce preventive measures for food safety and food safety. In addition, liability law could stimulate a culture within firms to take responsibility for food safety. Furthermore, our results confirmed that there are factors that encourage food safety measures in firms (market; food safety laws and regulations; product liability law). Altogether, it was indicated the opposite arguments to the positive insurance contribute of insurance to food safety and food security (insufficient knowledge with insurers; decreasing the financial incentive to produce safe food; insurers does not interact with food safety officers).

\section{References}

1. Feast or Famine: Business and Insurance Implications of Food Safety and Security, Lloyd's, 2013. Available at: https://www.lloyds.com/news-and-risk-insight/riskreports/library/society-and-security/food-report

2. Food safety in a globalised world: Keeping our food safe in the 21 st century. Swiss Reinsurance Company Ltd, 2015.

3. Elizabeth Haws Connally (2009). Good Food Safety Practices: Managing Risks to Reduce or Avoid Legal Liability. Food Safety and Technology. Available at: www.ctahr.hawaii.edu/oc/freepubs/pdf/FST-32.pdf

4. Food Safety and Liability Insurance. Massachusetts department of agricultural resources. UMass Extention: Center for Agriculture. Available at: https://ag.umass.edu/sites/ag.umass.edu/files/pdf-doc-

ppt/gap_food_safety_and_liability_insurance_0.pdf 
5. Omri Ben-Shahar (2015). Regulation of food safety through compulsory insurance. Law and Social Science 47, 14(2).

6. Tetty Havinga (2012). The Influence of Liability Law on Food Safety. On Preventive Effects of Liability Claims and Liability Insurance. SSRN Electronic Journal. DOI: 10.2139/ssrn.2016115

7. J.R. Skees et al. (2001). The potential for recall insurance to improve food safety. International and Agribusiness Management Review 4. P.99-111.

8. Cogan, Jr., John Aloysius (2016). The Uneasy Case for Food Safety Liability Insurance. Faculty Articles and Papers. 399. Available at: https://opencommons.uconn.edu/law_papers/ 399

9. Isaboke, H. N., Zhang, Q., Nyarindo W. N. (2016). The effect of weather index based micro-insurance on food security status of smallholders. Agricultural and Resource Economics: International Scientific E-Journal, [Online], vol. 2, no. 3, available at: www.are-journal.com

10. Bogdan Mârzaa, Carmen Angelescub, Cristina Tindecheb (2015). Agricultural Insurances and Food Security. The New Climate Change Challenges. Procedia Economics and Finance 27. P. 594-599.

11. How can we make insurance work for food security? Conference Report. Agricultural Insurance Conference. Nov 27-28 2014, Berlin.

12. The challenges of index-based insurance for food security in developing countries. Proceedings of a technical workshop organised by the EC Joint Research Centre $(J R C)$ and the International Research Institute for Climate and Society (IRI, Earth Institute, Columbia University). JRC Ispra, Italy, 2 and 3 May 2012.

13. Kathryn A. Boys (2013). Food Product Liability Insurance: Implications for the Marketing of Specialty Crops. The magazine of food, farm, and resource issues. 4th Quarter, №28(4).

14. Food safety and liability insurance. A community food security coalition report by Kristen Markley, Marion Kalb and Loren Gustafson. USDA Risk Management Agency Community Outreach and Assistance Partnership. 